\title{
Management of Chylous Ascites with Octreotide in a Bangladeshi Child: A Case Report
}

\author{
MOHAMMED NURULLAH ${ }^{1}$, A S M BAZLUL KARIM ${ }^{2}$, MD. RUKUNUZZAMAN ${ }^{3}$, MD. WAHIDUZZAMAN \\ MAZUMDER $^{4}$, FAHMIDA BEGUM ${ }^{5}$
}

\section{Introduction}

Congenital chylous ascites (CCA) is a rare disease that results from mal-development of the intraabdominal lymphatic system; characterized by accumulation of chylomicron-rich lymphatic fluid in the peritoneal cavity. ${ }^{1}$ The etiological factors of abdominal chylous ascites glycemicin the pediatric population can be primary or secondary. Abnormalities connected with the development and mat-uration of lymphatic vessels are the cause of the primary process. ${ }^{2,3}$ Dysplastic lymphatic vessels, both hypoand hyperplastic ones favor lymphatic leak-age in the mechanism of increasing pressure in the lym-phatic system, resulting lymphatic congestion. ${ }^{4,5}$ Delayed maturation of lymphatic vessels leading to abnormal structure of their walls, also results in lymphatic leakage to the peritoneal cavity. Developmental disorders of lymphatic vessels constitute the main cause of congenital chylous ascites found in newborns. The use of somatostatin and its analogue (octreotide) has recently been introduced into the management of iatrogenic chylothorax and chyloperitoneum in children. ${ }^{6,7}$ Probable mechanisms of action include decrease in lymph production and its flow rate. Octreotide has become popular drug for the treatment of chylous ascites because of its ease

1. Resident, Pediatric Gastroenterology \& Nutrition, Bangabandhu Sheikh Mujib Medical University (BSMMU), Dhaka, Bangladesh.

2. Professor \& Chairman, Pediatric Gastroenterology \& Nutrition, Bangabandhu Sheikh Mujib Medical University (BSMMU), Dhaka, Bangladesh.

3. Associate Professor, Pediatric Gastroenterology \& Nutrition, Bangabandhu Sheikh Mujib Medical University (BSMMU), Dhaka, Bangladesh.

4. Assistant Professor, Pediatric Gastroenterology \& Nutrition, Bangabandhu Sheikh Mujib Medical University (BSMMU), Dhaka, Bangladesh.

5. Assistant Professor, Pediatric Gastroenterology \& Nutrition, Bangabandhu Sheikh Mujib Medical University (BSMMU), Dhaka, Bangladesh.

Correspondence: Dr. Mohammed Nurullah, Department of Pediatric Gastroenterology \& Nutrition, Bangabandhu Sheikh Mujib Medical University (BSMMU), Shahabagh, Dhaka-1000, Bangladesh, E-mail: dr.nurullah35@gmail.com. in administration, low invasiveness, short treatment time and its high effectiveness. ${ }^{8}$ Here, we report a case of CCA in a child successfully treated with octreotide.

\section{Case report}

Omor Bin, a 5 year old boy only issue of his nonconsanguineous parents admitted with the complaints of abdominal distension since birth. He was diagnosed as a case of congenital cystic hygroma from antenatal ultrasonography(USG) and operated twice, one at $11 / 2$ months and another at 3 year of his age by a pediatric surgeon and also treated with sclerotherapy by local injection of sclerogent agent (Ethanolamine-N-Oleate). However, his condition didnot improve rather he had persistent ascites as shown by serial USG. He was mildly pale, non-icteric and vitals were within normal limit. Per abdominal examination showed abdominal distention with fullness of flanks and transverse umbilical slit. There were two scar marks, one at left lower abdomen and another at left lower back. He had no organomegaly but had ascites. The case was investigated and his ascetic fluid was milky white and triglyceride of ascetic fluid was $1718 \mathrm{mg} / \mathrm{dl}$. Octreotide was started, (Sandostatin; Novartis Pharmaceuticals China Ltd) in continuous intravenous infusion at a rate of $0.5 \mathrm{ig} / \mathrm{kg} / \mathrm{h}$ and gradually increased to $1.0 \mathrm{ig} / \mathrm{kg} / \mathrm{h}$ on day 3 of treatment and continued till 7 days and then tapered and discontinued on day 10 .

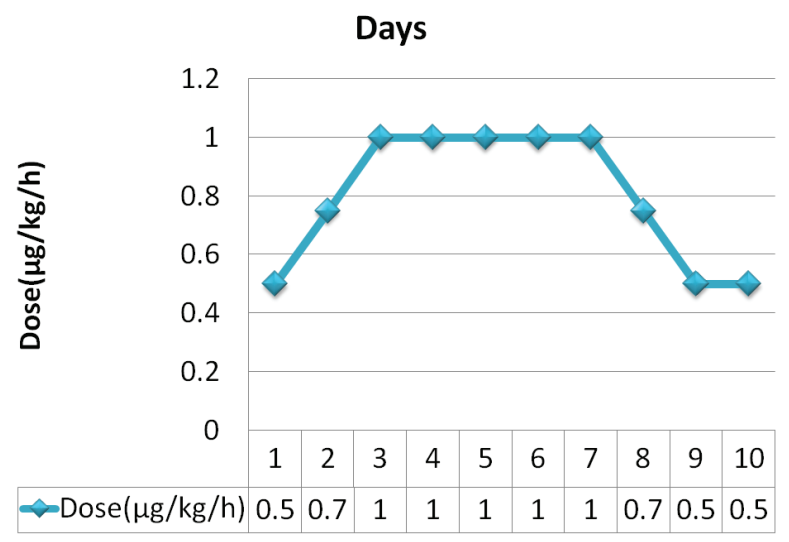

Fig-1: Doses of Octreotide. 
Twenty-four hours after starting octreotide, abdominal girth started decreasing. His abdominal girth decreased from $61 \mathrm{~cm}$ to $53 \mathrm{~cm}$ after completion of octreotide. Follow up USG shows no ascites. No side effects of octreotide, such as diarrhea, hypoglycemia or hyperglycemia, hypotension or liver dysfunction (including cholestasis) were noted throughout the whole treatment period.

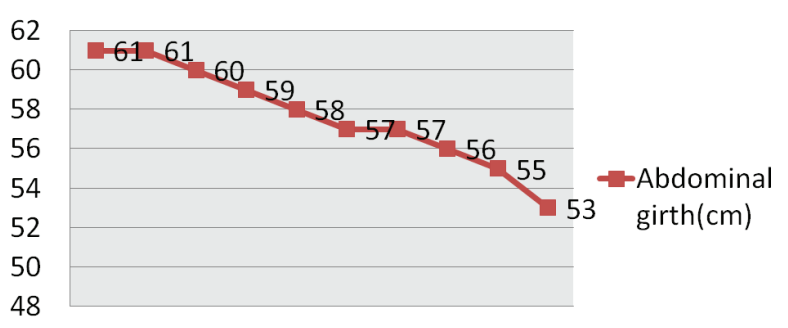

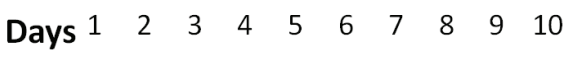

Fig-2: Abdominal girth after starting Octreotide.

Enteral feeding was well tolerated. The child was discharged from hospital in good condition with advice of medium chain triglyceride (MCT) based coconut oil to be used in cooking. Subsequent follow up after 2, 4 and 6 months by abdominal USG showed no signs of ascites.

\section{Discussion}

The main etiology of chylous ascites in children is congenital. There are many other causes of chylous ascites in children: idiopathic or obstructive lesions caused by mal-rotation, intussusception, incarcerated hernia, lymphangioma, blunt trauma, liver disease, and tuberculosis. ${ }^{9}$ The loss of lymphatic fluid causes hypoalbuminemia, hydro-electrolyte alterations, coagulation and immunodeficiency. ${ }^{10}$

Ultrasonography of the abdomen is the initial step that confirms the presence of ascites. Analysis of the fluid obtained by abdominal paracentesis is the most useful diagnostic method. The ascetic fluid known as chyle, is usually milky white. The appearance of the ascitic fluid depends on its composition, cellular substance and diet. The triglyceride content is usually markedly high. Furthermore, the true challenge is to determine the underlying cause of the chylousascites. The initial diagnostic investigation includes ultrasonography. Our case was diagnosed as congenitalcystic hygroma by antenatal ultrasonography. Further diagnostic tests like lymphangiography and lymphoscintigraphy can also be done with the purpose of identifying the site of the leakage of chyle. ${ }^{2,3}$

Treatment options for chylous ascitesare conservative and surgical. Conservative treatment is usually MCT based died with somatostatin analogue and surgical options are reductive surgery and sclerotherapy. ${ }^{11}$ Surgery is usually indicated after failure of conservative treatment. Surgery is an invasive procedure and requires expertise and is associated with significant morbidity and mortality. ${ }^{1}$ However, such procedure is limited by anatomic variations of the duct location, as well as difficulty to identify the leaking site. In this present case, surgery was done twice andsclerotherapyonce. Therefore, it is apparent that a pharmacologic agent that augments closure of the leak would be very valuable in the treatment of chylous effusion. Karagolet al. ${ }^{12}$ developed their own treatment scheme, according to which the therapy should begin with a few weeks of enteral nutrition with a diet including fat emulsion in the form of MCT. Next, enteral nutrition should be withheld and parenteral nutrition should be started with adminis-tration of somatostatin. The last stage is the surgery. Octreotide was first reported to significantly reduce chylous effusion in an adult with chylothorax ${ }^{13}$ and subsequently in several other patients with various etiology. ${ }^{14-18}$

Octreotide is a somatostatin analogue that inhibits the secretion of some pituitary and gastrointestinal hormones, reduce secretion of fluids from the intestine and pancreas, causes vasoconstriction in the blood vessels\& increases splanchnic arteriolar resistance, reducing gastrointestinal flow and consequently the lymph flow. ${ }^{17}$ It is a pharmacologic agent that also augments the closure of any leakage in the lymphatic system.

There are a few case reports in literature that use octreotide successfully to reduce chylous ascites. There are age and etiology variation. In addition, variationsregarding octreotide dosing regimens $(0.5-8 \mathrm{mcg} / \mathrm{kg} / \mathrm{h})$, modes of drug administration (intravenous or subcutaneous), commencement and duration of treatment have beenreported in the literature. ${ }^{15,16}$

We used octreotide by intravenous infusion at a rate of $0.5 \mathrm{ig} / \mathrm{kg} / \mathrm{h}$ and gradually increased to $1 \mathrm{ig} / \mathrm{kg} / \mathrm{h}$ on day 3 and continued till day 7 then tapered and discontinued on day 10. Huanget al. ${ }^{8}$ also used same dose and duration. A dramatic decrease in chyleproduction was observed within 24 hours of infusion, with complete resolution of ascites by 10 
days after treatment. Given the observed rapid resolution of chylous effusion concurrently with the octreotide administration, it appears that octreotide infusion rather than natural healing was responsible for the closure of chyle leakage and that is very promising.

It has some adverse effects like nausea, diarrhea, fatty stools, transient abdominal distension, liver dysfunction and transient glucose disturbance reported in pediatric population. ${ }^{12,18}$ In our case we followed up the patient blood pressure, capillary blood glucose but there were no significant adverse effects. Therefore, it can be said that a relatively low dose of $0.5-1.0 \mathrm{ig} /$ $\mathrm{kg} / \mathrm{h}$ of infusion seems to be sufficient for satisfactory outcome with minimal side effects.

\section{Conclusion}

The result found from the present study is encouraging with respect to drug safety and favorable outcome for the treatment of chylous ascites. We suggest that octreotide may be considered as an effective therapeutic option for management of pediatric chylous ascites.

\section{Message}

Medical management of chylous ascites with octreotide may be tried in unresponsive cases.

\section{References}

1. Cardenas A, Chopra S. Chylous ascites. Am J Gastroenterol. 2002;97:1896-900.

2. Steinemann DC, Dindo D, Clavien PA, Nocito A. ATraumatic Chylous Ascites: Systematic Review on Symptoms and Causes. J Am Coll Surg. 2011;212:899-908.

3. Romañska-Kita J, Borszewska-Kornacka MK, Dobrzañska A, Rudziñska I, Czech-Kowalska J, Wawrzoniak T. Congenital chylous ascites. Pol J Radiol. 2011;76:58-61.

4. Campisi C, Bellini C, Eretta C. Diagnosis and management of primary chylous ascites. J Vasc Surg. 2006;43:1244-48.

5. Talluri SK, Nuthakki H, Tadakamalla A, Talluri J. Besur S. Chylous Ascites. N Am J Med Sci. 2011;3:438-40.

6. Karaca S, Gemayel G, Kalangos A. Somatostation treatment of persistent chyloperitoneum following abdominal aortic surgery. J Vasc Surg. 2012;56:1409-12.
7. Al-Ghamdi MY, Bedi A, Reddy SB, Tanton RT, Peltekian KM. Chylous Ascites Secondary to Pancreatitis: Management of an Uncommon Entity Using Parenteral Nutrition and Octreotide. Dig Dis Sci. 2007;52:2261-64.

8. Huang $\mathrm{Y}$, Zhuang S, Li Y. Successful management of congenital chylous ascites in a premature infant using somatostatin analogue. Indian J Pediatr. 2011;78:345-47.

9. Romanska-Kita J, Borszewska-Kornacka MK, Dobrzañska A, Rudziñska I, Czech-Kowalska J, Wawrzoniak T. Congenital chylous ascites. Pol J Radiol. 2011;76:58-61.

10. Yang C, Zhang J, Wang S, LI C, Kong X, Zhao Z. Successful management of chylous ascites with total parenteral nutrition and octreotide in children. Nutr Hosp. 2013;28:2124-27.

11. Pessotti CFX, Jatene IB, Buononato PEU, Elias PF, Pinto ACD, Kok MFJ. Use of Octreotide in the Treatment of Chylothorax and Chyloperitoneum. Arq Bras Cardiol. 2011;97: 33-36.

12. Karagol B, Zenciroglu A, Gokce S. Therapeutic management of neonatal chylous ascites: report of a case and review of the literature. Acta Paediatr. 2010;99:1307-10.

13. Ulíbarri JI, Sanz Y, Fuentes C. Reduction of lymphorrhagia from ruptured thoracic duct by somatostatin. Lancet. 1990;336:258.

14. Kobayashi M, Kambara T, KamaiT. A Rare Complication of Chylous Leakage After Open Partial Nephrectomy Successfully Resolved by Somatostatin Analogue. Urology Case Reports. 2015;3:195-97.

15. Zhou DX, Zhou HB, Wang Q, Zou SS, Wang H, Hu HP. The Effectiveness of the Treatment of Octreotide on Chylous Ascites After Liver Cirrhosis. Dig Dis Sci. 2009;54:1783-88.

16. Kalay S, Oztekin O, Tezel G, Demir BE, Akcaku $\mathrm{M}$, Oygur N. Octreotidetreatment in a neonate with non-chylous pleural effusion. Afr J Paed Surg. 2013;10:374-76.

17. Purkait R, Saha A, Tripathy I, Roy B. Congenital chylous ascites treated successfully with MCTbased formula and Octreotide. J Indian Assoc Pediatr Surg. 2014;19:175-77.

18. Olivieri C, Nanni L, Masini L, Pintus C. Successful management of congenital chylous ascites with early octreotide and total parenteral nutrition in a newborn. BMJ Case Reports. 2012;10:1-4. 